\title{
Democracia sanitária: avanços e resistências no processo de participação dos pacientes/ usuários no sistema de saúde francês
}

\section{Sanitary democracy: advancements and resistance in the participation process of patients/users of the French healthcare system}

\section{Carlos Alberto Pegolo da Gama ${ }^{a}$}

(D) https://orcid.org/0000-0002-6345-7476

E-mail: carlosgamaळufsj.edu.br

\section{Mariana Dorsa Figueiredo ${ }^{b}$}

(D) https://orcid.org/0000-0001-6963-1968

E-mail: madorsaœhotmail.com

aUniversidade Federal de São João Del Rei. Curso de Medicina. Divinópolis, MG, Brasil.

bpôle de Ressources île de France en Éducation Thérapeutique du Patient. Paris, île de France, France.

\section{Correspondência}

Carlos Alberto Pegolo da Gama

Universidade Federal de São João Del Rei. Núcleo de Estudos e Pesquisas Psicossociais em Saúde. Curso de Medicina. Rua Sebastião Gonçalves Coelho, 400, Chanadour. Divinópolis, MG, Brasil. CEP 3550I-296.

\section{Resumo}

A discussão a respeito dos avanços dos cuidados em saúde passa pela questão da participação dos pacientes/usuários nas decisões a respeito de seu tratamento, dos seus direitos e de sua influência nas políticas públicas de saúde. O objetivo do presente artigo é fazer um breve histórico sobre a participação dos pacientes/usuários no sistema de saúde francês e apontar as principais conquistas e dificuldades presentes na atualidade. $\mathrm{O}$ artigo utiliza dados de arquivos oficiais, documentos produzidos por associações de pacientes e artigos de revistas especializadas. Na França, a participação dos pacientes faz parte de um cenário complexo que pode ser reconhecido no termo "Democracia Sanitária", que surge a partir da aproximação do campo da saúde e da política, propondo o questionamento das relações de poder estruturadas entre os atores e da possibilidade de um debate entre ciência e democracia. A epidemia da aids na década de 8o acompanhada de vários escândalos sanitários propiciou uma ruptura no modelo tradicional de estruturação das relações no campo da saúde produzindo uma mudança do status do paciente, de seu papel e de sua própria identidade através do fortalecimento do movimento associativo.

Palavras-chave: Sistema de Saúde; Participação da Comunidade; Movimento Associativo. 


\section{Introdução}

The discussion about advancements in healthcare involves the question of patient/user participation in decisions about their treatment, rights and influence on public health policies. This article thus outlines a brief history about the participation of patients/users of the French health system and to point out the main achievements and difficulties today. Three main sources were used: official archives, documents produced by patient associations, and journal articles. In France, patient participation is part of a complex scenario that can be seen in the term "Sanitary Democracy", which brought together health and politics, so that the structured power relations between patients and health professionals could be questioned and a debate between science and democracy could take place. The AIDS epidemic in the 1980s, followed by various health scandals, led to a break with the traditional model of structuring relationships in the health field, leading to change in the patient's status, role and identity through the strengthening of the associative movement.

Keywords: Health Systems; Community Participation; Associative Movement.
Historicamente a área da saúde apresenta uma forte tradição de concentração de poder nos técnicos e profissionais de saúde, aliada a uma concepção de que o paciente deveria ocupar um lugar passivo. Essa característica está ligada a um lento processo de consolidação da medicina como disciplina científica que tem início na metade do século XIX e se desenvolve por todo o século XX. Nesse período verifica-se a construção do paradigma biomédico, que exclui a subjetividade e enfatiza um saber técnico e hermético monopolizado pelos profissionais de saúde. Na primeira metade do século XX constata-se uma medicalização crescente e um alargamento do campo de atuação da medicina (reprodução assistida, saúde mental, infância). 0 discurso científico vai aos poucos tornando-se hegemônico e idealizado, o que produz uma série de consequências, dentre elas, o aumento do poder dos profissionais médicos e um modelo paternalista de relação com os pacientes (Bureau; Hermann-Mesfen, 2014).

Podemos identificar a partir da segunda metade do século XX o início de algumas transformações sociais, estruturais e ideológicas que fazem parte de um contexto mais amplo, mas vão influenciar a área da saúde. Identifica-se o fortalecimento dos valores do individualismo contemporâneo, como autonomia, autodeterminação e responsabilidade individual e a valorização dos ideais democráticos, reforçando as possibilidades de o indivíduo influenciar as questões de seu interesse. Ao mesmo tempo percebese o surgimento de propostas neoliberais que vão questionar o tamanho e o papel do Estado, visando cortes nas políticas públicas. Concomitante a este processo, observa-se, nos anos 6o, uma série de contribuições das ciências humanas e sociais para a área da saúde no sentido de questionar o paradigma biomédico, trazendo uma valorização da subjetividade e novas possibilidades de reflexão a respeito do sujeito com relação ao seu próprio corpo, à sua subjetividade e ao seu entorno social, impactando na visão tradicional do processo saúdedoença. 0 paciente deixa de ser visto como um objeto e passa a ser concebido como um sujeito e assiste-se ao começo do questionamento do poder delegado aos profissionais de saúde e a desmitificação do saber, 
abrindo espaço para uma série de problematizações sobre a relação paciente-profissional. No plano social destaca-se o movimento de maio 68 , o fortalecimento do feminismo e o aparecimento de movimentos ligados às minorias sexuais, de gênero etc. (Bureau; Hermann-Mesfen, 2014; Guedes; Nogueira; Camargo Junior, 2006).

Aliado a estes fatores, temos que as transformações relacionadas aos avanços da medicina, a transição demográfica, as mudanças nos padrões de consumo e nos estilos de vida, a urbanização acelerada, entre outras, modificaram as características das populações, alterando seu perfil epidemiológico e nutricional e provocando um aumento das taxas de morbimortalidade por problemas crônicos de saúde. Esta situação produz transformações nos sistemas de saúde, induzindo mudanças na maneira de organizar os cuidados às doenças crônicas, exigindo o estabelecimento de uma relação de longo prazo entre paciente e profissional, assim como a abordagem de como o paciente vivencia sua doença (Mendes, 2011).

Outro fator importante é o aumento da influência da indústria farmacêutica dentro do sistema de saúde em todos os níveis, alcançando os pacientes, as associações, os gestores, os órgãos de regulação, os universitários, os pesquisadores, o ministério da saúde e os responsáveis políticos. As grandes empresas multinacionais controlam tanto o planejamento e financiamento das publicações científicas quanto a produção, a divulgação e venda destes produtos. Elas investem e trabalham para obter influência nos diversos setores, muitas vezes apresentando fortes indícios de conflito de interesses. Identifica-se também um debate intenso em torno da utilização do paradigma dominante da gestão do setor privado comercial na administração pública, privilegiando a visão do usuário enquanto consumidor em detrimento do cidadão (Goupil et al., 2019; OMS, 2013).

\section{Um breve cenário sobre o tema da participação}

O conceito de participação é bastante complexo pois está presente em diferentes áreas do conhecimento e sofre transformações ligadas aos diferentes contextos históricos no qual é investigado. Ele tem forte ligação com as teorizações sobre democracia, o princípio de igualdade dos cidadãos e as formas de distribuição do poder. Podemos defini-la como um processo pelo qual as pessoas, grupos ou organizações podem se envolver ativamente na definição dos problemas que lhes dizem respeito, tomando decisões sobre os fatores que afetam suas vidas, formulando e implementando políticas, planejando, desenvolvendo e participando de ações que possibilitem mudanças. (Bresson, 2014; WHO, 2002).

Nos modelos democráticos mais conservadores, a participação limita-se à atuação dos eleitos no campo da política institucional. Nos modelos mais avançados há uma ampliação das possibilidades de participação através da descentralização das tomadas de decisão e inclusão de atores de diferentes níveis sociais. Partese do pressuposto que a ampliação da participação permitiria maior capacidade de interrogação do sistema vigente, produzindo uma maior adequação das tomadas de decisão relativas às necessidades da maioria da população. No entanto, ela pode responder a diferentes lógicas e racionalidades, muitas vezes contraditórias com relação aos objetivos propostos. Seu uso é bastante dinâmico, havendo oscilações na medida que as possibilidades de participação são progressivamente institucionalizadas e de certa forma instrumentalizadas pelos sistemas representativos vigentes e demais atores. Assim, embora muitas das iniciativas de participação social surjam do desejo legítimo individual ou coletivo dos cidadãos, ocorrem situações em que ela é utilizada como ferramenta para validação ou legitimação de interesses contrários aos reais interesses coletivos. Dessa forma, muitos movimentos que num primeiro momento possuem força para questionar determinada situação, na sequência vão perdendo a capacidade e a potência transformadora (Carpentier, 2011).

As propostas de ampliação das responsabilidades individuais através do empoderamento da população são um exemplo de como o tema da participação pode ser usado de maneira ambígua. Elas podem tanto ser compreendidas como aumento da autonomia e valorização do coletivo como, de outro lado, podem ser utilizadas pelo discurso neoliberal visando a superação da lógica da assistência, propondo uma transferência de responsabilidade e isentando o Estado de fornecer a proteção social. Outra tendência 
identificada é a despolitização do tema da participação quando é incorporada a campos diversos associados a conceitos como capital social, responsabilidade social das empresas, gestão corporativa, governança, terceiro setor, entre outros ligados principalmente a novas técnicas de administração. Nessa mesma linha identifica-se propostas de ampliação do direito de escolha dos participantes nas quais ele é concebido como consumidor (em vez de cidadão) de bens e serviços oferecidos por uma multiplicidade de produtores e prestadores, preferencialmente privados (Bresson, 2014; Vianna; Cavalcanti; Cabral, 2009).

Neste artigo estamos interessados no conceito de participação na saúde com vistas à construção conjunta de autonomia (no âmbito individual e coletivo), que envolve grande diversidade de atores que se relacionam dentro de um cenário com suas leis, políticas sociais, associações, sindicatos etc. Nosso objetivo é apontar o desenvolvimento das diversas formas de participação no contexto francês e as mudanças ocorridas a partir de acontecimentos chaves neste processo.

\section{A construção das possibilidades de participação}

Nossa abordagem do problema parte do pressuposto de que o aumento da participação tem estreita relação com as mudanças nas concepções dos pacientes/usuários, dos profissionais de saúde e consequentemente das instituições de saúde. Nesse sentido, as primeiras tentativas, por parte dos pacientes, de transformação deste campo visando mais autonomia e poder de decisão, começam a partir de meados do século XX, ligadas à psiquiatria. Podemos citar a experiência dos Alcoólicos Anônimos na década de 1930 nos Estados Unidos, com a proposta de ajuda mútua entre pessoas dependentes de álcool, e o movimento da antipsiquiatria na década de 1950, que questiona o modelo hospitalar e as práticas médicas. O movimento das pessoas que vivem com deficiências também contribui para estas transformações, tentando garantir direitos através do fortalecimento de propostas oriundas de pessoas que vivem o problema (Gross, 2017; Lascoumes, 2007).

Essas experiencias iniciais servirão de base para transformações que ocorrerão a partir da década de 80 na França. Observa-se alguns pontos comuns, como a ausência de resposta da medicina aos problemas vivenciados, a existência de uma rejeição social (estigma), a mistura de fatores individuais, psicológicos e sociais e a capacidade de auto-organização. Neste sentido, a ação coletiva propicia transformações na capacidade de assumir individualmente a doença, produz mudanças na relação paciente/profissional e politiza a questão dentro do domínio da saúde (Lascoumes, 2007).

No final dos anos 1970, a Organização Mundial de Saúde reconhece os direitos e os deveres dos cidadãos de participar tanto individualmente como coletivamente na organização e no funcionamento de seus sistemas de saúde. Esta proposta foi incorporada pelos países de diferentes maneiras, com diferentes níveis de regulamentação e diferentes dispositivos de expressão e reconhecimento das opiniões dos pacientes, usuários e cidadãos.

Bousquet e Ghadi (2017), analisando as experiências estrangeiras relacionadas à participação dos pacientes/ usuários nos sistemas de saúde, identificaram três grandes modelos colocados em prática. $\mathrm{O}$ primeiro, identificado como modelo estratégico, foi estruturado em torno de associações de representantes de pacientes que participam das discussões e decisões na área da saúde no plano nacional ou local. Trata-se de integrar a visão do usuário como cidadão - e não paciente - nas decisões relativas à organização dos cuidados, acessibilidade, financiamento e avaliação do sistema de saúde. Eles citam a experiência alemã nos anos 9o, em que os representantes dos cidadãos começam a ter lugar nos conselhos de administração dos planos de assistência à saúde; nos Países Baixos, as associações de pacientes são consultadas nos diferentes níveis de decisão; no Reino Unido o National Health Service integra a participação dos cidadãos nas instâncias de decisão e no Canadá, as províncias de Quebec e Ontário também possuem experiências bem estruturadas neste sentido. No Brasil este modelo aparece na organização dos conselhos municipais, estaduais e nacional de saúde, em que representantes de usuários do SUS participam das decisões sobre a gestão do sistema.

O segundo modelo relaciona-se à implicação de usuários nos estabelecimentos de saúde para gestão das reclamações e defesa de direitos. São reconhecidas as experiências dos "patient 
representative" nos Estados Unidos e Reino Unido, e os chamados "mediadores" nos países nórdicos (ombudsman). Nos Países Baixos a participação acontece através de plataformas regionais, e na Inglaterra, da "comissão de qualidade dos cuidados". A experiência mais próxima da francesa é a do Quebec, através da implantação dos "comitês de usuários" que visam informar os pacientes sobre seus direitos e obrigações, defender os direitos individuais e coletivos e promover a qualidade dos serviços (Bousquet; Ghadi, 2017).

0 terceiro modelo relaciona-se à implicação de pessoas doentes ou hospitalizadas, incluindo os familiares, na definição e no desenvolvimento de cuidados, em parceria com os profissionais de saúde. Este modelo é utilizado a nível internacional pelas instituições e serviços ligados à promoção, eficiência e melhora da qualidade e segurança dos cuidados em saúde. Está ligado à visão dos cuidados centrados no paciente que propõe implicar individualmente e coletivamente os usuários nos serviços de saúde. Isso pressupõe uma valorização do saber da experiência e das preferências dos pacientes na construção de soluções conjuntas. Como exemplo temos o modelo de "patient advisor" nos Estados Unidos, os programas de "patients partenaire" no Quebec e de "patient leader" na Inglaterra (Bousquet; Ghadi, 2017). Levando em conta esta divisão, a experiência francesa de participação situa-se principalmente no segundo e terceiro modelos.

\section{O histórico da participação no Sistema de Saúde Francês}

A área da saúde pública na França estruturouse de maneira mais intensa a partir do final do século XX e não tinha tradição com relação à participação dos usuários nas decisões públicas. Sua organização sempre foi marcada pela centralização, com dificuldades de adaptação às especificidades regionais. Não existia uma proximidade entre os cidadãos e as instâncias de decisão, e os representantes eleitos não faziam uma consulta à população para propor leis ou regulamentações na área da saúde. Da mesma forma, os gestores utilizavam, na maioria das vezes, comitês de experts para embasar as decisões, sofrendo muitas vezes pressões políticas e econômicas que divergiam dos interesses da coletividade (Tabuteau, 2013).

Alguns autores apontam que o início do processo de "humanização dos hospitais" na década de 1950 pode ser considerado precursor das mudanças com relação ao aumento da participação dos pacientes no sistema de saúde. As propostas da OMS na década de 1970 a respeito da participação dos pacientes e da saúde comunitária foram assimiladas de maneira muito frágil na França, e a mobilização social a respeito da saúde está ligada às reinvindicações iniciais em torno de parcerias possíveis e de como os pacientes poderiam colaborar para melhorar a prática médica (Saout, 2017).

O processo de participação na França esteve sempre mediado pelas associações de pacientes e familiares, que existem desde o início do século XX. Identifica-se uma evolução no tipo de engajamento e nas posturas adotadas pelas associações com relação ao seu papel social e às formas de participação. Estas transformações dependem das diferentes concepções a respeito do tipo de ação desenvolvida, de qual deve ser seu posicionamento público e dos tipos de conhecimento mobilizados. Tem relação também com a distribuição de papéis sociais e de poder dos diferentes atores do sistema de saúde e a relação entre eles: pacientes, familiares, médicos e profissionais de saúde, autoridades públicas, pesquisadores e empresas da área. Deve-se levar em conta os modos de exercício da medicina em vigor em determinado momento e as concepções sobre cada patologia e seu desenvolvimento terapêutico (Barbot; Fillion, 2007).

Até os anos 1950 prevalece o modelo associativo baseado na caridade, através das ligas filantrópicas que são formadas principalmente por mulheres e políticos que organizam coletas de fundos destinadas às pesquisas das doenças. Este modelo é marcado pelo chamado "paternalismo médico conservador", que de um lado definia as diretrizes do tratamento e avaliava os resultados, e de outro concedia pouca autonomia aos pacientes. Identifica-se uma relação carregada de julgamentos morais sobre a conduta dos pacientes que favorecia a estigmatização e desmoralização (Barbot; Fillion, 2007).

Como indicamos na introdução, a partir dos anos 50 começaram algumas transformações sociais 
e ideológicas que afetaram a sociedade como um todo na medida que tensionaram a estrutura da sociedade tradicional, colocando em questão as relações de gênero, a família, a sexualidade e a própria noção de democracia. Na mesma direção a antropologia, as ciências sociais e a psicologia construíram um novo referencial teórico que valorizava a subjetividade e o ambiente na construção do processo de cuidado (Guedes; Nogueira; Camargo Junior, 2006).

Num primeiro momento assistimos à passagem do chamado paternalismo médico tradicional para uma postura mais liberal, na qual o modo de cooperação entre os médicos, os pacientes e seus familiares é concebido a partir de uma divisão de papéis, em que os especialistas cuidam das questões tecno-científicas, e os doentes e familiares cuidam das dimensões psicossociais da doença. Uma das explicações para esta mudança está ligada às novas necessidades trazidas pela cronicidade das doenças, na medida que o paciente deve gerenciar diariamente sua doença e implementar os tratamentos propostos que, na maioria das vezes, são complexos e restritivos. 0 papel das associações neste modelo é de ensinar os pacientes e familiares a realizar parte dos cuidados e proporcionar compartilhamento de experiências visando superar dificuldades e melhorar o cuidado (Barbot; Fillion, 2007; Lascoumes, 2007).

Aos poucos os profissionais começam a perceber os limites da abordagem científica (paradigma biomédico) na saúde, que é baseada num alto nível de abstração, tende a descontextualizar a situação da doença e não consegue expressar o fenômeno na sua integridade. Neste sentido, tem início uma valorização da percepção singular que o paciente tem de seu processo de adoecimento, que depende de sua história e de fatores socioculturais. Assim, cada sujeito é portador de uma experiência e de um saber específico ligado à sua forma de vivenciar o problema, da sua relação com ele mesmo que enriquece o conhecimento abstrato do especialista, desde que possa ser expresso e ouvido (Lascoumes, 2007).

Ao mesmo tempo o saber médico tradicional se depara com várias incertezas e situações de impotência relacionadas à complexidade dos sintomas, aos limites do tratamento, aos efeitos colaterais, e mesmo falhas nos serviços de saúde, diminuindo a idealização e a crença no poder e no caráter estritamente benfeitor da medicina. Em decorrência destes fatores ocorrem mudanças de postura e consolida-se o entendimento que somente um bom conhecimento científico não é suficiente para garantir um bom cuidado e que os saberes práticos complementam o cuidado. Estas transformações colocam em xeque o poder técnico paternalista e desestabilizam instituições e profissionais (Lascoumes, 2007).

No entanto, é somente partir da década de 80 que transformações mais profundas nas relações de poder entre pacientes/usuários e profissionais de saúde começam a tomar corpo, ligadas à ocorrência de diversos escândalos e crises sanitárias.

A epidemia da aids na década de 80 pode ser considerada como evento chave nestas transformações, acompanhada de uma série de escândalos sanitários, como a contaminação de pacientes hemofílicos pelo vírus HIV, infecção após cirurgias na Clínica do Esporte, problemas relacionados à hormônios de crescimento (doença de Creutzfeld-Jacko) e ao consumo de frango (dioxine). Este conjunto de problemas criam uma crise de confiança na biomedicina e os pacientes começam a tomar consciência da incerteza da prática médica, questionando posturas e interesses, tanto corporativos como empresariais, por trás dos tratamentos e propostas dos profissionais de saúde. Esses fatos também produziram investigações criminais que identificaram responsabilidades em altos escalões do Estado, nas diversas esferas da administração pública e nas instituições de direito privado ligadas à saúde (Barbot; Fillion, 2007; Géraldine; Fillion, 2009).

A epidemia da aids produziu uma grande mobilização social pelo elevado número de casos, as mortes e as características sociodemográficas da população atingida. Num primeiro momento este cenário provocou medo e aumento da estigmatização, no entanto, isso produziu uma transformação na implicação dos pacientes com relação ao seu tratamento. Eles constituíram grupos de pressão que reivindicaram mudanças nas relações de poder com os profissionais de saúde e espaço nas instâncias de decisão institucionais. As associações 
conquistaram um lugar na Agência Nacional de Pesquisa contra a Aids, influenciaram nas políticas públicas propondo ações preventivas e questionaram o saber/poder da medicina, propondo parcerias visando a complementaridade entre o saber experiencial e o saber científico. Abriram espaço para um novo modelo de relação com a esfera pública, fundado na legitimação do conhecimento dos pacientes e na participação sistemática nas decisões.

O escândalo do "sangue contaminado" na década de 90 refere-se à contaminação massiva de pacientes hemofílicos tratados com produtos derivados do sangue, pelo vírus HIV. Esta situação repercutiu na confiança dos usuários nos procedimentos de saúde e no sistema de saúde como um todo, incluindo a comunidade médica, os funcionários do setor administrativo e produziu um grande questionamento político. A Associação Francesa dos Hemofílicos desempenhou papel fundamental neste processo pois modificou sua postura tradicional de apoio aos médicos e instituições de saúde e assumiu a defesa dos pacientes, entrando com um processo coletivo para punir os culpados. Possibilitou também condições para que seus membros adquirissem expertise científica, aumentando o poder de participação nas políticas públicas (Géraldine; Fillion, 20o9; Mougeot et al., 2018).

Outro exemplo importante está relacionado à segurança dos pacientes com relação aos procedimentos ligados à saúde. A associação Lien (Luta, Informação e Estudos das Infecções Nosocomiais) foi criada após o escândalo ocorrido na Clínica do Esporte em 1997, no qual diversos pacientes que passaram por cirurgias foram infectados pela bactéria Xenopi e ficaram com graves sequelas. A criação da associação e a denúncia do problema à imprensa coloca em visibilidade as infecções nosocomiais e a transforma em problema de saúde pública. A discussão ganha nível nacional e são criados indicadores públicos de resultados em matéria de prevenção das infecções hospitalares. Aos poucos o campo de ação é ampliado e começa uma luta por direitos à informação dos pacientes e medidas de proteção com relação ao conjunto dos acidentes médicos (Letourmy; Naïditch, 2009; Rambaud, 2008).

Esta concomitância de escândalos desestabilizou a antiga organização e abriu espaço para uma mudança de paradigma, pois foi necessário reconstruir a confiança das pessoas no sistema de saúde.

No que concerne à relação dos pacientes/ usuários membros de associações e os profissionais de saúde percebe-se a consolidação de um novo modelo, no qual a cooperação entre profissional e usuário se legitima dentro de um quadro de relações mais simétricas. Este reequilíbrio passa pelo reconhecimento do paciente como sujeito e do usuário como interlocutor. A palavra do paciente ganha um outro estatuto no qual o saber médico geral e abstrato deve dialogar com o saber experiencial, individual e encarnado para identificar as necessidades, os objetivos e a participação de cada um no processo de decisão tornando os dois saberes indissociáveis. Observa-se novos modos de governança no meio associativo, a redefinição das relações de poder entre profissionais e pacientes, a implicação crescente dos doentes na gestão dos riscos sanitários e a renovação das construções identitárias ligadas à doença (Lascoumes, 2007).

Todas estas transformações nas relações de poder vão influenciar mudanças na legislação no sentido de ampliar os direitos e a representação dos pacientes e usuários na área da saúde. Dentre elas destaca-se a lei relativa aos direitos e a proteção das pessoas hospitalizadas em razão de transtornos mentais e a sua condição de hospitalização (France, 1990), a lei sobre a reforma hospitalar que assegura a livre escolha do médico pelo paciente e acesso às informações contidas no prontuário médico (France, 1991) e a lei da bioética que introduz no código civil a obrigação do consentimento do doente (France, 1994). Em 1996 é promulgada a chamada "lei Juppé" (lei de financiamento da seguridade social e Reforma Hospitalar) que consagra seu primeiro título aos direitos dos doentes e faz da qualidade do atendimento um objetivo essencial (France, 1996). Ela prevê uma representação dos usuários da saúde no Conselho de Administração de cada estabelecimento público de saúde e nas instâncias regionais e nacional.

\section{Os Estados Gerais da Saúde}

Diante do cenário instalado pelos movimentos de pacientes nas décadas de 1980 e 1990, o Ministério da Saúde Francês, em parceria com o Coletivo 
Interassociativo sobre a Saúde (Ciss), propõe em 1998 os Estados Gerais da Saúde, com objetivo de dar a palavra aos pacientes e usuários através de novos métodos de participação. Foi uma resposta do governo às diversas críticas endereçadas ao sistema de saúde com relação às desigualdades, à falta de segurança sanitária e de transparência das decisões e ações em saúde. Esta iniciativa foi baseada em experiências anteriores de Estados Gerais ligados a aids, diabetes e câncer. No entanto, difere delas na medida que não está dominada pelo ponto de vista dos profissionais mas sim pelo protagonismo dos pacientes que tomam a palavra conferindo um tom mais emotivo e engajado às discussões (Brucker; Caniard, 1999; Lascoumes, 2007).

A proposta de organização dos Estados Gerais da Saúde foi de descentralizar os debates com a criação de Comitês Regionais de discussão, os chamados "fóruns cidadãos", que elaboraram recomendações que seriam levadas ao fórum nacional. 0 processo durou em torno de 9 meses e contou com a participação de aproximadamente 150.00o pessoas das diversas regiões da França em mais de 1000 reuniões, mostrando o envolvimento e o desejo das pessoas em participar mais ativamente das discussões e decisões com relação à saúde (Lascoumes, 2007). Foram debatidos temas relacionados ao acesso ao sistema, à relação médico/ paciente, aos direitos dos pacientes, à transparência do sistema, à educação em saúde, à participação dos usuários nas decisões, entre outros. O resultado foi apresentado em um relatório que serviu de base para a lei relativa aos direitos dos pacientes e à qualidade do sistema de saúde. No capítulo da lei dedicado à democracia sanitária, identifica-se uma nova forma de governança em torno de um tripé formado pelo reconhecimento dos direitos dos pacientes, o direito dos usuários do sistema de saúde e a responsabilidade dos profissionais. Ela fortalece os direitos dos pacientes e o papel das associações de saúde (Cardin, 2014).

Com relação à participação dos pacientes nos cuidados e no tratamento, a lei reconhece o direito à informação médica, envolvendo os atos e os riscos, a informação sobre as condições tarifárias e a regra do consentimento e da cooperação no cuidado.
Identifica-se a criação das comissões de relações com os usuários e de qualidade do atendimento em cada estabelecimento de saúde e permite a participação das associações de usuários no acompanhamento dos serviços prestados. Ao mesmo tempo a lei exige garantias de representatividade das associações que necessitam de uma autorização regional ou nacional para exercer sua missão.

Outro capítulo da lei refere-se ao fortalecimento da responsabilidade dos profissionais de saúde. A lei instaura novas obrigações de transparência, desde a declaração de acidentes médicos, mas também suas relações com empresas que produzam ou comercializem produtos de saúde. Observa-se um reforço ao direito do paciente de obter reparação em caso de erro médico (Letourmy; Naïditch, 2009).

O reconhecimento legal dos direitos dos pacientes permite uma melhora no equilíbrio das relações de poder sendo que os avanços produzidos fortalecem sobretudo as demandas isoladas e as associações menores que não possuem muito poder. A nova lei defende a concepção de decisão compartilhada e contribui para erradicar a postura paternalista tão presente na classe médica.

\section{As associações e o protagonismo dos pacientes/usuários}

No contexto dessas transformações há o fortalecimento do movimento associativo que começa a se expandir e atuar de maneira mais intensa no cenário da saúde. Algumas associações nasceram ligadas às urgências de saúde pública (aids, hepatite), outras relacionadas aos avanços científicos e do tratamento (doenças raras, câncer e doenças cardiovasculares), outras ligadas às questões de minorias sociais (usuários de drogas, transexuais). Elas formam um conjunto bastante heterogêneo, composto por uma diversidade de propósitos em termos de objeto social, natureza das ações, composição e representações nos diversos níveis. Elas também possuem missões diversificadas tais como: informação, acolhimento, apoio e acompanhamento, sensibilização pública, desenvolvimento e gestão de programas sociais, acesso aos cuidados e aos direitos, participação em pesquisas e em programas 
de prevenção, experimentação de propostas interdisciplinares e de redes (Berthod-Wurmser et al., 2017; Lecimbre et al., 2002).

Aos poucos as associações constroem alianças e redes tanto verticais como horizontais, auxiliadas pelas novas tecnologias de informação (internet) e por processos de capacitação e profissionalização. Num movimento transversal, diversas associações que defendiam causas mais específicas, por exemplo, ligadas a uma doença ou problema de saúde, começam ampliar seu campo de ação e se associar em função de problemas globais das políticas de saúde, como a qualidade da informação ao paciente, segurança hospitalar, a escolha de opções terapêuticas, a necessidade de um cuidado psicossocial, os problemas de acesso e os direitos dos usuários (Lascoumes, 2007).

Um marco importante foi a criação do Ciss em 1996 ao mesmo tempo da promulgação da Reforma Hospitalar (lei Juppé). Esta iniciativa teve como objetivo unir forças e organizar o movimento associativo para responder as novas propostas contidas na lei e formular reinvindicações coletivas às instituições de saúde. Nesse momento as associações conquistam o acesso aos Conselhos de Administração dos estabelecimentos de saúde. No começo o Ciss contava com 15 associações participantes e funcionava como polo aglutinador do movimento associativo. Em 2004 passa de uma plataforma associativa sem estatuto jurídico para a forma jurídica de associação e já agrega 26 das principais associações nacionais de pessoas doentes, de pessoas portadoras de deficiência, de consumidores e de familiares, adquirindo uma representatividade nacional. Em 2017, após mais de 20 anos de mobilização, o Ciss é transformado em "France Assos Santé" que representa a União Nacional de Associações dos Usuários do Sistema de Saúde e torna-se uma das referências para representá-los e defender seus direitos, sendo reconhecida oficialmente por lei. É importante destacar a dimensão interassociativa característica da France Assos Santé, que dá sua legitimidade de representação. Ela se inscreve numa dinâmica progressivamente instalada pelo movimento associativo a partir de 1996 com a criação do Ciss. Há um trabalho essencial no quotidiano das associações que se refere às trocas entre os associados e entre grupos de trabalhos em torno de temáticas prioritárias nos diversos domínios. 0 resultado destes grupos e trocas produz reflexões coletivas que embasam a tomada de decisão dos representantes das associações.

Atualmente a France Assos Santé reagrupa 80 associações que reúnem centenas de milhares de pacientes portadores de todos os tipos de doenças crônicas. Ela desenvolve ações em 4 eixos prioritários: formação de representantes dos usuários; observação e acompanhamento do funcionamento e das transformações do sistema de saúde visando garantir sua equidade; informação aos usuários sobre seus direitos; e comunicação aos diversos atores a respeito das situações encontradas e das reinvindicações em curso, bem como das estratégias de ação comuns.

Neste contexto destaca-se também a ampliação e generalização da representação nas instâncias da saúde no nível local, regional, nacional e internacional. As associações tornam-se um ator importante como interlocutor dos usuários nos debates com os poderes públicos, ao mesmo tempo em que realizam ações de informação, formação e proposições concretas no sentido de reforçar os direitos dos usuários.

\section{0 paciente-ator}

As experiências relatadas têm em comum o incremento do poder de participação dos usuários/ pacientes na área da saúde, que é acompanhada do reconhecimento de um protagonismo e a passagem da condição de atores individuais para atores coletivos. Ao mesmo tempo constata-se o desenvolvimento de expertises no campo dos direitos individuais e coletivos, na cultura de compartilhamento de experiências e saberes adquiridos com a vivência cotidiana das doenças e nos modos de ação com relação às políticas e sistemas de saúde. Consolidase a figura do paciente-ator ancorada no saber experiencial e na capacidade de diálogo com outros saberes (Flora, 2013; Mougeot et al., 2018).

Este processo tem impactos na assistência, na formação de profissionais e na pesquisa em saúde. Percebe-se um questionamento a respeito de como o 
conhecimento é produzido, no sentido de superar a clivagem existente entre saber experiencial e saber científico. Assim, após uma formação específica, pacientes "experts" passam a intervir junto aos profissionais de saúde, favorecendo a expressão de outros pacientes e sua capacidade de diálogo com os profissionais. Na mesma linha, assumem o estatuto de pesquisadores em pareceria com universidades e de formadores junto a estudantes da área da saúde, contribuindo para uma melhor identificação e resposta às expectativas das pessoas que vivem com uma doença crônica.

Na assistência em saúde a participação dos pacientes desenvolve-se no âmbito do modelo de Educação Terapêutica do Paciente (ETP), que visa ajudar os pacientes com doenças crônicas a adquirir competências para melhor gerir sua vida com a doença: compreender a doença e o tratamento; compartilhar decisões com os profissionais; manter ou melhorar sua condição de saúde e sua qualidade de vida. Inclui atividades de sensibilização, informação, aprendizagem, autogestão e apoio psicossocial relativos à doença, ao tratamento, aos cuidados, à hospitalização, aos serviços de saúde e aos comportamentos ligados à saúde e à doença.

Tradicionalmente a ETP era desenvolvida nos hospitais pelo corpo técnico, centrada na doença e na transmissão descendente de informações. Este cenário se modifica na medida que o papel do paciente vai se transformando e o hospital vai deixando de ser o lugar exclusivo destas práticas que começam a se expandir para o território. Este processo consolida-se a partir de 2008 quando a legislação começa a exigir a participação de pacientes em todas as etapas (elaboração, concepção, realização e avaliação) do processo de ETP (Traynard; Gagnayre, 2013).

Outro eixo de ação diz respeito a participação de pacientes "experts" na formação de estudantes da área da saúde e em pesquisas sobre doenças, modelos de assistência ou organização de serviços de saúde. A colaboração no ensino e na pesquisa visa implicar de maneira equitativa os atores no processo, transferindo competências de ensino e pesquisa através de metodologias colaborativas. Isso permite valorizar os aspectos éticos e as necessidades dos usuários, assim como constituir um corpo de saberes validados e reconhecidos a partir da experiência de viver com uma doença e o trabalho de autorreflexão que ela suscita (Gross; Gagnayre, 2017; Tourette-Turgis, 2010).

\section{Considerações finais}

O processo de construção da democracia sanitária na França apresenta muitos avanços na medida que as diversas iniciativas individuais e os movimentos sociais conseguiram produzir uma massa crítica a respeito da participação e do papel dos usuários/pacientes neste cenário. Há relativo consenso por parte dos diversos atores sociais da importância de se assegurar que haja a intervenção de um saber experiencial que conserve a dimensão emocional e afetiva, criando uma interface entre a sociedade civil de um lado e as instituições médicas e administrativas de outro, permitindo que as decisões não sejam tomadas somente por uma visão técnica dos experts e administradores. A dissimetria de posição entre profissionais de saúde e usuários foi reduzida tanto pelo acesso massivo à internet como pelo reconhecimento dos direitos e o estabelecimento de regras para mediar os conflitos. 0 movimento associativo se fortaleceu e através da representação dos pacientes/usuários do sistema sustenta diversos espaços de formação propiciando uma participação mais qualificada (Chambaud; Schaetzel, 2009; Lascoumes, 2007).

As transformações nos modos de cuidado, geradas com a participação dos usuários nas intervenções de ETP são importantes: melhoria da assistência ao paciente (aumento das taxas de satisfação, melhor aceitação dos cuidados, melhores resultados); resposta mais completa e melhor integrada às necessidades do paciente e sua família; orientações clínicas mais compreensíveis e portanto mais eficazes; diminuição da frequência e melhor manejo dos episódios agudos da doença; reconhecimento do saber experiencial; responsabilidade e tomada de decisão compartilhadas; desenvolvimento da competência da equipe de saúde; aumento da satisfação da equipe devido à melhoria da qualidade dos cuidados aos pacientes. Com relação à colaboração entre pacientes e profissionais na pesquisa e na formação em saúde, a perspectiva dos pacientes permite questionar os hábitos e as decisões 
dos profissionais, trazendo novos olhares e novas percepções sobre o processo de cuidado.

Apesar dos avanços, identificam-se questionamentos a respeito dos limites da representação das associações, que muitas vezes se distanciam dos usuários sofrendo influência dos interesses do poder público, das corporações profissionais e da indústria farmacêutica. São colocadas questões a respeito do processo de escolha dos representantes, qual é o campo de competência desta representação e qual seu real poder de intervenção (Letourmy; Naïditch, 2009; Saout, 2017; Tabuteau, 2013).

Outro foco de questionamento recai sobre as modalidades de financiamento na medida que as subvenções públicas não podem financiar as novas formas de participação coletiva. Sem transparência e sem regulamentação do poder público, a legitimidade e a credibilidade das novas formas de representação podem ser questionadas. Percebe-se, por exemplo, que os laboratórios farmacêuticos já identificaram estes novos atores e começam a propor financiamentos. Identifica-se a necessidade de um posicionamento mais claro do governo a respeito do tema pois corre-se o risco de o movimento ser financiado por setores que não tem como objetivo principal o fortalecimento da democracia sanitária e a melhora da qualidade e segurança do cuidado no Sistema de Saúde (Lascoumes, 2007; Le Cam, 2001).

Uma outra questão importante relaciona-se ao espaço cada vez maior ocupado dentro da saúde por atores privados e por uma gestão de tipo administrativo, isto é, uma governança que privilegia uma lógica ligada à performance do sistema e aos aspectos financeiros. Nesta visão o usuário é considerado muito mais como um cliente do que como um cidadão. A democracia sanitária é sustentada por uma outra lógica que privilegia a economia social e a gestão cooperativa. A questão principal a compreender é se é possível esta convivência e que tipo de intervenção do governo é necessária para que isto aconteça.

Os processos de participação são dinâmicos e, de maneira geral, tendem a perder força com o passar do tempo. As conquistas realizadas, na medida que sofrem um processo de ordenamento institucional podem ser neutralizadas ou instrumentalizadas mudando o foco de interesse inicial. A sustentabilidade destes avanços e conquistas necessita um movimento contínuo de participação, reflexão e reposicionamento para que não percam sua potência inovadora e transformadora.

\section{Referências}

BARBOT, J.; FILLION, E. La dynamique des victimes: les formes d'engagement associatif face aux contaminations iatrogènes (VIH et prion). Sociologie et Sociétés, Montréal, v. 39, n. 1, p. 217-247, 2007.

BERTHOD-WURMSER, M. et al. Patients et usagers du système de santé: l'émergence progressive de voix qui commencent à compter. Revue Française des Affaires Sociales, Paris, v. 1, p. 5-19, 2017.

BOUSQUET, F.; GHADI, V. La participation des usagers aux systèmes de santé: un tour d'horizon international. Revue Française des Affaires Sociales, Paris, v. 1, p. 116-127, 2017.

BRESSON, M. La participation: un concept constamment réinventé, Socio-logos, Marseille, n. 9, 2014. Disponível em: <https://bit.ly/ 3qMZ96U>. Acesso em: 21 abr. 2019.

BRUCKER, G.; CANIARD, E. États généraux de la santé: une démarche innovante pour plus de démocratie sanitaire. Actualité et Dossier en Santé Publique, Paris, n. 27, p. 6-9, 1999.

BUREAU, E.; HERMANN-MESFEN, J. Les patients contemporains face à la démocracie sanitaire. Anthropologie \& Santé, Marseille, n. 8, 2014. Disponível em: <https://bit.ly/2ZE4th9>. Acesso em: 2 jun. 2014.

CARDIN, H. La loi du 4 mars 2002 dite "loi Kouchner”. Les Tribunes de la Santé, Marseille, n. 42, p. 27-33, 2014. Disponível em: <https://bit.ly/ 3dAOXL7>. Acesso em: 22 fev. 2021.

CARPENTIER, N. The concept of participation: if they have access and interact, do they really participate? Casopis za Upravljanje Komuniciranjem, Belgrade, v. 21, p. 13-36, 2011.

CHAMBAUD, L.; SCHAETZEL, F. Participation citoyenne et système de santé: démocratisation ou instrumentalisation? Santé, Société \& Solidarité, Lyon, n. 2, p. 35-43, 2009. 
FLORA, L. Savoirs expérientiels des malades, pratiques collaboratives avec les professionnels de santé: état des lieux. Education Permanente, Paris, n. 195, p. 59-72, 2013.

GÉRALDINE, B.; FILLION, E. À l'épreuve du sang contaminé: pour une sociologie des affaires médicales. Paris: Éditions de l'École des Hautes Études en Sciences Sociales, 2009.

GOUPIL, B. et al. Association between gifts from pharmaceutical companies to French general practitioners and their drug prescribing patterns in 2016: retrospective study using the French Transparency in Healthcare and National Health Data System databases. $B M J$, London, v. 367, art. 16015, 2019.

GROSS, O. L'engagement des patients au service du système de santé. Paris: Doin, 2017.

GROSS, O.; GAGNAYRE, R. La participation des usagers comme cochercheurs: état des Lieux des pratiques collaboratives dans les éducations en santé. In: CARRIER, S. L'engagement de la personne dans les soins de santé et services sociaux: regards croisés France-Québec. Québec: Presses de l’Université du Québec, 2017. p. 117-133.

GUEDES, C. R.; NOGUEIRA, M. I.; CAMARGO JUNIOR, K. R. A subjetividade como anomalia: contribuições epistemológicas para a crítica do modelo biomédico. Ciência \& Saúde Coletiva, Rio de Janeiro, v. 11, n. 4, p. 1093-1103, 2006.

LASCOUMES, P. L'usager dans le système de santé: réformateur social ou fiction utile? Politiques \& Management Public, Marseille, v. 25, n. 2, p. 129-144, 2007.

LE CAM, Y. Le rôle des associations dans le respect et l'observation des droits individuels et collectifs. Actualité et Dossier en Santé Publique, Paris, n. 36, p. 30-33, 2001.

LECIMBRE, E. et al. Le rôle des associations de patients dans le développement de l'éducation thérapeutique en France. Santé Publique, Saint-Maurice, v. 14, n. 4, p. 389-401, 2002.
LETOURMY, A.; NAÏDITCH, M. L'émergence de la démocratie sanitaire en France. Santé, Société \& Solidarité, Lyon, n. 2, p. 15-22, 2009.

FRANCE. Loi ${ }^{\circ}$ 90-527, du 27 juin 1990. Relative aux droits et à la protection des personnes hospitalisées en raison de troubles mentaux et à leurs conditions d'hospitalisation. Journal Officiel de la République Française, Paris, 30 jun. 1990. Disponível em: <https://bit.ly/3rcypgi>. Acesso em: 2 mar. 2021.

FRANCE. Loi no ${ }^{0}$ 1-748, du 31 juillet 1991. Portant réforme hospitalière. Journal Officiel de la République Française, Paris, 2 ago. 1991. Disponível em: <https://bit.ly/3baYZ3Y>. Acesso em: 2 mar. 2021.

FRANCE. Loi nº 94-653, du 29 juillet 1994.

Relative au respect du corps humain. Journal Officiel de la République Française, Paris, 30 jul. 1994. Disponível em: <https://bit.ly/3dZizlH>. Acesso em: 2 mar. 2021.

FRANCE. Loi Organique no 96-646, du 22 juillet 1996. Relative aux lois de financement de la sécurité sociale. Journal Officiel de la République Française, Paris, 23 jul. 1996. Disponível em: <https://bit. ly/2PnA3h7>. Acesso em: 2 mar. 2021.

MENDES, E. V. As redes de atenção à saúde. Brasília, DF: Organização Pan-Americana da Saúde, 2011.

MOUGEOT, F. et al. L'émergence du patient-acteur dans la sécurité des soins en France: une revue narrative de la littérature entre sciences sociales et santé publique. Santé Publique, Paris, v. 30, n. 1, p. 73-81, 2018.

OMS - ORGANISATION MUNDIALE DE LA SANTÉ. Comprendre la promotion pharmaceutique et $y$ répondre: un manuel pratique. Genève, 2013.

RAMBAUD, C. Les décisions ont une histoire: les infections nosocomiales. Santé Publique, Paris, v. 2o, n. 4, p. 353-356, 2008.

SAOUT, C. 100 lignes sur la democratie sanitaire. Paris: Éditions de Santé, 2017.

TABUTEAU, D. Démocracie sanitaire: les nouveaux défis de la politique de santé. Paris: Odile Jacob, 2013. 
TOURETTE-TURGIS, C. Savoirs de patients, savoirs de soignants: la place du sujet supposé savoir en éducation thérapeutique. Pratiques de Formation/Analyses, Saint-Denis,

n. 58/59, p. 137-144, 2010.

TRAYNARD, P. Y.; GAGNAYRE, R. $\bar{\varepsilon}$ ducation thérapeutique du oatient en ville et sur le territoire. Paris: Maloine, 2013.
VIANNA, M. T. W.; CAVALCANTI, M. L.; CABRAL, M. P. Participação em saúde: do que estamos falando? Sociologias, Porto Alegre, v. 11, n. 21, p. 218-251, 2009.

WHO - WORLD HEALTH ORGANIZATION. Community participation in local health and sustainable development: approaches and techniques. Copenhagen, 2002. Disponível em: <https://bit.ly/3dI7vt7>. Acesso em: 25 ago. 2020.

\section{Agradecimentos}

Agradecemos a colaboração dos pesquisadores Michel Naiditch (pesquisador do Institut de Recherche et Documentation en Economie de la Santé), Thomas Sannié (coordenador administrativo e responsável pelo eixo "Parcerias entre Profissionais e Pacientes" do Pôle de Ressources - Île de France - en Education Thérapeutique du Patient e representante de usuários em instancias de saúde da região Île de France) e Pierre Yves Traynard (coordenador do Pôle de Ressources - Île de France - en Education Thérapeutique du Patient) pela colaboração no decorrer da pesquisa com informações e indicações de fontes bibliográficas fundamentais para o desenvolvimento deste trabalho.

\section{Contribuição dos autores}

Pegolo da Gama concebeu e delineou o projeto e redigiu o manuscrito. Dorsa Figueiredo analisou o material e realizou a revisão crítica do artigo. Ambos os autores aprovaram a versão a ser publicada.

Recebido: 12/06/2020

Reapresentado: 26/08/2020

Aprovado: 09/09/2020 